Reports on the peoples of a particular region will be assembled in accordance with the general plan and issued together with a critical bibliography and a series of maps showing tribal and other distributions.

The Survey will include essential data on the nomenclature, linguistic affiliations and distributions of tribal and other groups. It will outline the salient features of the demography, economic life, social organization, and other cultural features of each people and provide a critical bibliography covering these fields. In order that it shall be as widely useful as possible, some indication of the character and scope of the agencies of modern development and of the trends of social and economic change will be given.

Work has already started on the systematization of material in Britain relating to Tanganyika and adjacent areas in East Africa and to Nigeria in West Africa. It is desirable to amplify and correct existing published data as early as possible by the study of unpublished material in the colonial territories. For this the support and co-operation of the Colonial Offices, the Governments of the several territories and of non-official bodies will be sought as the Survey progresses.

The Survey is being conducted with the advice of a committee of experts under the chairmanship of Professor A. R. Radcliffe-Brown. A panel of consultants is being set up to secure the collaboration of ethnographers and other experts overseas. Professor I. Schapera of the University of Cape Town and Dr. Max Gluckman, Director of the Rhodes-Livingstone Institute, have consented to act as correspondents and regional organizers for the work in Southern and South-central Africa.

It is realized that during the present period of emergency, which involves a severe strain on the depleted staffs of the official and other services in Colonial territories, only limited requests can be made for assistance with reference to local records. But assistance is invited from all field workers, administrative, educational and technical officers in the Colonial services and the staffs of missionary and other organizations who have, or can direct us to, unpublished material likely to be of value. A more detailed account of the scope and proposed arrangements of the Survey will be sent to any who can assist in this way.

\title{
The Institute's Card Catalogue of Africanist Literature
}

Considerable progress has been made by the Librarian in the preparation of a card catalogue of published literature covering the fields with which the Institute is concerned. The catalogue, which is classified under author, regional, and subject headings, has been based for the more recent years on the current bibliography appearing regularly in Africa. This has been supplemented and entries are also being carried back to include earlier publications. Special efforts are being made to fill gaps in information derived from continental and African publications. Although the work will require some time to complete, it is sufficiently far advanced to be of use to students and is available in the Library for all members of the Institute.

\section{Ethnographic Reconnaissance in the Gambia}

THE Director, Prof. Daryll Forde, visited the Gambia in May last at the invitation of the Governor in order to ascertain in a brief field reconnaissance the needs and opportunities for anthropological studies likely to be required in connexion with plans for the further development of native administration.

\section{Membership}

MEMBERSHIP of the Institute is increasing; over seventy new members have joined since January 1945. The circulation of this Journal is limited by paper control restrictions. The attention of members whose subscriptions are in arrears is called to the notice printed in the January 1945 issue of Africa. 